\title{
Response Inhibition Function of Obsessive-Compulsive Patients with Obsessive-Compulsive Personality Disorder
}

\author{
Hui Lei ${ }^{1}$, Jie Fan ${ }^{2,3}$, Cheng Zhou ${ }^{2}$, Jiaojiao Dong ${ }^{2}$, Xiongzhao Zhu ${ }^{2,3^{*}}$ \\ ${ }^{1}$ College of Education, Hunan Agricultural University, Changsha 410128, P.R. \\ China; \\ ${ }^{2}$ Medical Psychological Center, The Second Xiangya Hospital, Central South \\ University, P.R. China; \\ ${ }^{3}$ Medical Psychological Institute of Central South University, P.R. China.
}

*Corresponding to: Xiongzhao Zhu. Email: xiongzhaozhu@163.com.

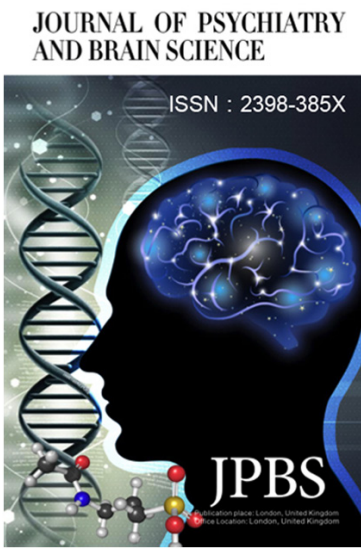

http://jpbs.qingres.com

\section{GOPEN ACCESS}

DOI: $10.20900 / j p b s .20170011$

Received: March 22, 2017

Accepted: May 24, 2017

Published: June 25, 2017

Copyright: $\odot 2017$ Cain et al. This is an open access article distributed under the terms of the Creative Commons Attribution License, which permits unrestricted use, distribution, and reproduction in any medium, provided the original author and source are credited.

\begin{abstract}
Objective: To explore the effect of comorbid obsessive-compulsive personality disorder (OCPD) on response inhibition functions in patients with obsessive-compulsive disorder (OCD).

Methods: Forty-five obsessive-compulsive patients with obsessivecompulsive personality disorder (OCD + OCPD), 42 obsessivecompulsive patients without obsessive-compulsive personality disorder (OCD - OCPD) and 54 healthy volunteers were selected for the stopsignal task.
\end{abstract}

Results: Obsessive-compulsive patients with obsessive-compulsive personality disorder had a higher score of depression and anxiety and more severe obsessive-compulsive symptoms than that of obsessivecompulsive patients without obsessive-compulsive personality disorder. The two groups of obsessive-compulsive patients of had a greater stop-signal reaction time (SSRT) during the inhibition process than the healthy volunteers of the control group (OCD + OCPD: $221.45 \pm 31.78$; OCD - OCPD: $218.36 \pm 31.78$; Controls: $199.29 \pm 22.80 ; p<0.05$ ). However, no significant difference was found between the two groups of obsessive-compulsive patients.

Conclusion: The findings show that the comorbid obsessivecompulsive personality disorder has no effect on response inhibition function of obsessive-compulsive patients.

Keywords: Obsessive-compulsive disorder; Obsessive-compulsive personality disorder; Response inhibition; Comorbidity

Obsessive-compulsive disorder (OCD) is a common mental disorder 
clinically characterized by repeated obsessions and / or compulsions, as well as concomitant anticompulsions and competent pains. OCD is often comorbid with a personality disorder (PD), most commonly OCPD, of which the comorbidity rate is $23 \%-32 \%{ }^{[1]}$. Some studies have shown that OCD patients with OCPD were characterized by a severer compulsive symptom, an earlier age of onset and weaker response to drug treatment ${ }^{[2-4]}$. Based on the difference of clinical manifestations, some researchers believed that OCD comorbid with OCPD might be a sub-type of the OCD ${ }^{[2,3]}$. However, the results of these studies were not consistent. For example, Lochner, et al. found that no earlier age of onset was found among the OCD patients with OCPD, and that there was no difference in treatment effect on cognitive behavior ${ }^{[5]}$.

Previous studies showed that the OCD patients were subject to a deficiency of the response inhibition function ${ }^{[6,7]}$. This deficiency of cognitive function might be one of the major pathologic factors of the obsessive-compulsive disorder and could be explained as the core symptom of the OCD to a certain extent; namely, obsessive thoughts resulting from the unsuccessful inhibition of intrusive ideas and obsessive behavior resulting from the unsuccessful inhibition of ritual acts or behaviors ${ }^{[8]}$. Some researchers explored the relationship between the obsessive-compulsive disorder and the obsessive-compulsive personality disorder from the perspective of cognitive functions by using neuropsychological methods. They found that OCD patients with OCPD had poorer cognitive flexibility compared with the OCD patients without OCPD ${ }^{[9]}$. In this study, neuropsychological methods were also used to explore the effect of comorbid obsessivecompulsive personality disorder on the response inhibition functions of the OCD patients.

\section{SUBJECTS AND METHODS}

\subsection{Subjects}

There were 87 OCD patients in this study and they were outpatients from psychological department of the Second Xiangya Hospital from 2013 to 2015, including 54 male patients and 33 female patients, aged 18 - 40 years old, with a mean age of $24.35 \pm 4.96$ years. All patients conformed to the OCD diagnosis criteria of the fourth edition of the Diagnostic and Statistical Manual of Mental Disorders (DSM-IV) and they had no history of other mental illnesses, neurological disorders, or severe physical illness. Forty-five of these patients complied with the OCPD diagnosis criteria of the Structured Clinical Interview for DSM (SCID-II) and they were included into the comorbidity group (OCD + OCPD); the other 42 patients were not associated with OCPD and they were included into the noncomorbidity group (OCD - OCPD); 54 healthy volunteers were recruited from communities and universities as the subjects of control group, and they were reported without history of mental illness, central nervous disease, drug abuse, or major physical illness. All subjects were reported with normal or corrected normal eyesight, without color blindness, or dextromanuality, and they had signed informed consents and voluntarily participated in this study. This study was approved by the medical ethics committee of our hospital.

\subsection{Experimental Assignments}

The Stop-Signal Task (SST) was used to test the response inhibition function of the subjects. The subjects were required to perform a simple reaction time task ("go" task), that is, make the key-pressing response (press the space key) when the "go" stimulus (letter "X") appears in the computer screen. SST included two types of tests, namely, 'go' tests (accounting for $70 \%$ ) and 'stop' tests (accounting for $30 \%)$. In the "go" tests, only "go" stimulus appeared. In the "stop" tests, letter "X" would be changed from black to red. This color change was a stop signal, suggesting that the subjects needed to inhibit the key-pressing response. The initial value of "go" stimulus and stop-signal distance (SSD) was 250 $\mathrm{ms}$, and the change of SSD was calculated using the ladder algorithm. If the subjects successfully inhibited the key-pressing response, the SSD of next "stop" test would increase by $50 \mathrm{~ms}$, otherwise it reduced by $50 \mathrm{~ms}$. Before the formal experiment, an exercise of 20 tests was performed so that the subjects could master the key-pressing operation and experiment requirements. 400 tests (including 120 "stop" tests) were required for the formal experiment. The subjects had a resting period of 1 minute every 100 tests.

\subsection{Test Questionnaires}

General situation questionnaires were used to collect demographic data, medical history, disease course and other clinical data; The Yale-Brown Obsessive Compulsive Scale (Y-BOCS) was used to assess the symptom severity of OCD patients; Beck Depression Inventory (BDI-II) and State-Trait Anxiety Inventory (STAI) were used to assess the depression and anxiety level of all subjects. 


\subsection{Statistical Data}

The difference of ages, education levels, depressions, anxieties and behavioral outcomes of the subjects in the three groups was analyzed and compared using one-way analysis of variance (ANOVA) analysis, and a statistical comparison of the gender ratio was performed with a Chi-squared test. Results were corrected for multiple comparisons using Bonferroni correction. The independent twosample t-test was used for the comparison between the OCD + OCPD and the OCD - OCPD group, respectively. The two-sided tests were used for the
F-test and t-test, and the one-side test were used for the Chi-squared test. We used the significance level of 0.05. All statistical analyses were completed using the statistical software package SPSS19.0.

\section{RESULTS}

\subsection{Demographic Data and Scale Scores}

The statistical results of demographic data and scale scores of the subjects in three groups are shown in Table 1.

Table 1. Statistical Results of Demographic Data and Scale Scores

\begin{tabular}{|c|c|c|c|c|c|c|c|}
\hline \multirow[t]{2}{*}{ Variable } & $\begin{array}{c}\text { OCD-OCPD } \\
\text { Group } \\
(\mathrm{n}=42)\end{array}$ & $\begin{array}{c}\text { OCD + OCPD } \\
\text { Group } \\
(n=45)\end{array}$ & $\begin{array}{l}\text { Control Group } \\
\qquad(\mathrm{n}=54)\end{array}$ & \multirow[t]{2}{*}{ Statistics } & \multirow[t]{2}{*}{$\mathrm{p}$ Value } & \multirow[t]{2}{*}{$\begin{array}{c}\text { Effect } \\
(\eta 2)\end{array}$} & \multirow[t]{2}{*}{$\begin{array}{l}\text { Post hoc } \\
\text { analysis }\end{array}$} \\
\hline & Mean(SD) & Mean(SD) & Mean (SD) & & & & \\
\hline Age & $25.01(4.72)$ & $23.73(5.15)$ & $23.13(4.10)$ & $1.98 \mathrm{a}$ & 0.14 & & \\
\hline $\begin{array}{l}\text { Gender Ratio } \\
\text { (male/female) }\end{array}$ & $27 / 15$ & $27 / 18$ & $37 / 17$ & $0.78 \mathrm{~b}$ & 0.68 & & \\
\hline $\begin{array}{l}\text { With/Without } \\
\text { Medicine }\end{array}$ & $31 / 11$ & $30 / 25$ & & $0.53 b$ & 0.47 & & \\
\hline $\begin{array}{l}\text { Education } \\
\text { Years }\end{array}$ & $12.48(1.23)$ & $12.29(1.52)$ & $12.72(1.38)$ & $1.22 \mathrm{a}$ & 0.30 & & \\
\hline BDI-II Scores & $18.98(10.75)$ & $23.98 .50(10.80)$ & $6.89(5.74)$ & $45.03 a$ & $<0.001$ & 0.40 & $\begin{array}{c}\text { OCD+OCPD, } \\
\text { OCD-OCPD > } \\
\text { Controls; OCD } \\
\text { + OCPD > } \\
\text { OCD-OCPD }\end{array}$ \\
\hline SAI Scores & $51.03(14.12)$ & $58.26(16.20)$ & $36.07(10.07)$ & $34.50 \mathrm{a}$ & $<0.001$ & 0.34 & $\begin{array}{c}\text { OCD + OCPD, } \\
\text { OCD-OCPD > } \\
\text { Controls; OCD } \\
\text { + OCPD > } \\
\text { OCD-OCPD }\end{array}$ \\
\hline TAI Scores & $54.18(9.53)$ & $58.02(8.41)$ & $40.39(7.62)$ & $59.51 \mathrm{a}$ & $<0.001$ & 0.47 & $\begin{array}{c}\text { OCD + OCPD } \\
\text { OCD-OCPD > } \\
\text { Controls }\end{array}$ \\
\hline
\end{tabular}

Notes: BDI-II: Beck Depression Inventory; SAI: State Anxiety Inventory; TAI: Trait Anxiety Inventory; OCD - OCPD: Noncomorbidity group; OCD + OCPD: comorbidity group; Control: control group; a F value of ANOVA; b X2 value of the Pearson's Chi squared test. 
No significant difference was found in age, gender ratio, or education years of the subjects in the three groups. The depression and anxiety scores of OCD subjects in the two groups were significantly higher than that of the control group, and significant difference was also found between the two groups of obsessive-compulsive patients.

The comparison results of clinical differences of two groups of obsessive-compulsive patients are shown in Table 2. As shown in the table, no significant difference was found in onset age and disease course of the two groups, but a significant difference was found in the Y-BOCS total scores, Obsessive scores, and Compulsive scores. Furthermore the score of OCD + OCPD Group was higher than that of OCD - OCPD Group (Y-BOCS: 30.27 vs $25.63, p<0.05$; Obsessive: 16.02 vs 14.33 , $p<0.05$; Compulsive: 14.24 vs $11.30, p<0.05$ ).

Table 2. Statistical Results of Clinical Characteristics of Non-Comorbidity Group and Comorbidity Group

\begin{tabular}{|c|c|c|c|c|c|c|}
\hline \multirow{2}{*}{ Variable } & \multicolumn{2}{|c|}{ OCD-OCPD $(n=42)$} & \multicolumn{2}{|c|}{ OCD+OCPD $(n=45)$} & \multirow{2}{*}{$\mathrm{t}$} & \multirow{2}{*}{$p$ value } \\
\hline & Mean & SD & Mean & SD & & \\
\hline Onset Age (Years old) & 18.14 & 5.67 & 17.30 & 5.85 & 0.63 & 0.53 \\
\hline Disease Course (Years) & 7.29 & 3.61 & 6.67 & 4.96 & 0.62 & 0.54 \\
\hline Y-BOCS Score & 25.63 & 6.98 & 30.27 & 8.26 & 2.06 & $<0.05$ \\
\hline Obsessive Score & 14.33 & 3.60 & 16.02 & 3.99 & 2.93 & $<0.05$ \\
\hline Compulsive Score & 11.30 & 4.65 & 14.24 & 4.60 & 2.78 & $<0.05$ \\
\hline
\end{tabular}

Notes: Y-BOCS: Yale-Brown Obsessive Compulsive Scale; OCD - OCPD: Non-Comorbidity Group; OCD + OCPD: Comorbidity Group.

\subsection{Behavioral Results}

There was no significant difference in mean reaction time and correct rate and other behavioral indicators of the three groups of subjects in the "Go" tests $(p$ $>0.05$ ), see Table 3. Neither was there a significant difference in the success rate in "Stop" tests $(p>$ 0.05). However, there was a significant difference of stop-signal reaction time (SSRT) between the three groups $(p<0.05)$. We found that there was a significant difference between two OCD groups and control group $(p<0.05)$, and the SSRT of OCD OCPD group and OCD + OCPD group was greater than that of control group $(p<0.05)$. However there was no significant difference in SSRT between two OCD groups $(p>0.05)$. Because of the significant difference in symptom severity of two OCD groups, the difference between the two groups was compared using the Y-BOCS score as the covariate. The comparison results showed no significant difference in SSRT indicators of two OCD groups ( $F$ $=0.429, p=0.524$ ). 
Table 3. Statistical Results of Behavioral Data for the Subjects of Three Groups

\begin{tabular}{|c|c|c|c|c|c|c|c|}
\hline \multirow[t]{2}{*}{ Variable } & $\begin{array}{c}\text { OCD-OCPD } \\
(n=42)\end{array}$ & $\begin{array}{c}\text { OCD + OCPD } \\
(n=45)\end{array}$ & $\begin{array}{l}\text { Control } \\
(\mathrm{n}=54)\end{array}$ & \multirow{2}{*}{ x2 Value } & \multirow{2}{*}{$p$ Value } & \multirow[t]{2}{*}{$\begin{array}{c}\text { Effect } \\
(\eta 2)\end{array}$} & \multirow{2}{*}{ Post hoc analysis } \\
\hline & Mean(SD) & Mean(SD) & Mean(SD) & & & & \\
\hline $\begin{array}{l}\text { Go Correct } \\
\text { Rate (\%) }\end{array}$ & $0.93(0.04)$ & $0.94(0.05)$ & $0.93(0.05)$ & 0.99 & 0.37 & & \\
\hline $\begin{array}{l}\text { GoReaction } \\
\text { Time (ms) }\end{array}$ & $\begin{array}{c}650.57 \\
(159.42)\end{array}$ & $\begin{array}{c}607.13 \\
(159.12)\end{array}$ & $\begin{array}{c}625.13 \\
(141.07)\end{array}$ & 0.89 & 0.41 & & \\
\hline $\begin{array}{l}\text { Success } \\
\text { Rate (\%) }\end{array}$ & $0.59(0.07)$ & $0.59(0.07)$ & $0.61(0.07)$ & 1.06 & 0.35 & & \\
\hline SSRT (ms) & 218.36(31.78) & $221.45(37.66)$ & $199.29(22.80)$ & 7.59 & $<0.05$ & 0.10 & $\begin{array}{l}\text { OCD-OCPD, } \\
\text { OCD+OCPD > } \\
\text { Controls }\end{array}$ \\
\hline
\end{tabular}

Notes: SSRT: Stop-signal reaction time; OCD - OCPD: Non-comorbidity Group; OCD + OCPD: Comorbidity Group; Control: Control Group. X2: Pearson's chi squared test.

\section{DISCUSSION}

The present study results showed that OCD patients with OCPD had a higher level of depression and anxiety and more severe obsessive-compulsive symptoms than that of OCD patients without OCPD, which is consistent with the previous studies. For example, Gao, et al. ${ }^{[10]}$ found that the symptoms of OCD + OCPD group was more severe than that of OCD - OCPD group. This suggests that the OCD + OCPD has aggravated the severity of OCD.

In this study, the SST was used to test the response inhibition function of OCD patients with or without OCPD. In this task, SSRT is the effective behavior indicator. The longer the SSRT is, the longer the time required for individuals to inhibit the response will be, reflecting a worse response inhibition function ${ }^{[11]}$. The longer SSRT of comorbidity group and non-comorbidity group than that of the control group indicates a reduced response inhibition function of OCD patients. This result is consistent with the previous study results ${ }^{[6,7]}$. However, there is no SSRT difference between two groups of OCD patients, which indicates that the associated OCPD did not cause additional damage to the response inhibition functions of OCD patients. The previous studies found that the associated OCPD would aggravate the damage of cognitive function of OCD patients. For example, Fineberg, et al. ${ }^{[9]}$ found a poorer cognitive flexibility in the comorbidity group after the comparison of cognitive flexibility between OCD patients with OCPD and OCD patients without OCPD. However, no similar conclusion was drawn in this study, which reflects that the co-morbid OCPD may not aggravate the impairment of all associated cognitive functions, rather it may only affect some of these cognitive functions.

As an important executive function, response inhibition function is regarded as one of the causes of obsessive-compulsive symptoms (i.e. repeated obsessive thought or obsessive behavior) ${ }^{[8]}$. The deficiency phenomenon of cognitive functions is also found in other personality disorders like marginal personality disorder. One of the characteristics of the marginal personality disorder is impulsivity. Ruchsow, et al. ${ }^{[12]}$ found that the deficiency of response inhibition control was found in the patients with the marginal personality disorder. However, the 
deficiency or defect of response inhibition function has not yet been reported or confirmed in the OCPD patients up to now. The core clinical characteristics of the obsessive-compulsive personality disorder are the focus on details and mechanical perfectionism, etc. These may be related to the cognitive flexibility and are mechanistically unrelated to the response inhibition control function. This may be the reason a more severe response inhibition function defect was not found in this study.

There are some limitations for this study: obsessive-compulsive personality disorder group (OCPD - OCD) was not included in this study and it is necessary to add such a clinical control group to further clarify the overlap or specific relationship of OCD to OCPD in clinical characteristics and response inhibition function characteristics; furthermore, only behavioral data was obtained in this study and thus, electroneurophysiological or neuroimaging techniques should be used to explore the neurophysiological characteristics of OCD patients with OCPD in the future.

In conclusion, the study result shows that comorbid OCPD will not aggravate the impairment of response inhibition functions of OCD patients, which indicates that OCPD only partially affects the same cognitive functions as of the OCD patients.

\section{FUNDING SUPPORT}

This paper was supported by the Natural Science Foundation of Hunan Province China (grant No. 2016JJ3067).

\section{REFERENCES}

1. Samuels J, Nestadt G, Bienvenu OJ, Costa PT Jr, Riddle MA, Liang KY, Hoehn-Saric R, Grados MA, Cullen BA. Personality disorders and normal personality dimensions in obsessivecompulsive disorder. $\mathrm{Br} J$ Psychiatry. 2000; 177(5): 457-462.

2. Coles ME, Pinto A, Mancebo MC, Rasmussen SA, Eisen JL. OCD with comorbid OCPD: a subtype of OCD? J Psychiatr Res. 2008; 42(4): 289-296.

3. Garyfallos G, Katsigiannopoulos K, Adamopoulou A, Papazisis G, Karastergiou A, Bozikas VP.
Comorbidity of obsessive-compulsive disorder with obsessive-compulsive personality disorder: Does it imply a specific subtype of obsessivecompulsive disorder? Psychiatry Res. 2010; 177(1): 156-160.

4. Pinto A, Liebowitz MR, Foa EB, Simpson HB. Obsessive compulsive personality disorder as a predictor of exposure and ritual prevention outcome for obsessive compulsive disorder. Behav Res Ther. 2011; 49(8): 453-458.

5. Lochner C, Serebro P, der Merwe L, Hemmings S, Kinnear C, Seedat S, Stein DJ. Comorbid obsessive-compulsive personality disorder in obsessive-compulsive disorder (OCD): A marker of severity. Prog Neuropsychopharmacol Biol Psychiatry. 2011; 35(4): 1087-1092.

6. Lei H, Zhu X, Fan J, Dong J, Zhou C, Zhang $X$, Zhong $M$. Is impaired response inhibition independent of symptom dimensions in obsessive-compulsive disorders? Evidence from ERPs. Sci Rep. 2015; 5: 10413.

7. Liu W, Zhu W. Association Analysis between Attention Inhibition and Symptoms of Firstepisode Obsessive-Compulsive Disorder. J Intl Psychiat. 2016; 43 (2): 203-205.

8. Chamberlain SR, Blackwell AD, Fineberg NA, Robbins TW, Sahakian BJ. The neuropsychology of obsessive compulsive disorder: the importance of failures in cognitive and behavioral inhibition as candidate endophenotypic markers. Neurosci Biobehav Rev. 2005; 29: 399-419.

9. Fineberg NA, Sharma P, Sivakumaran T, Sahakian B, Chamberlain SR. Does obsessivecompulsive personality disorder belong within the obsessive-compulsive spectrum? CNS spectr. 2007; 12(6): 467-482.

10. Gao X, Geng D, Zhou C, Xiao W. Research on Obsessive-compulsive Disorder Comorbided with Obsessive-Compulsive Personality Disorder. J Clin Psychiat. 2016; 26 (5): 320-322.

11. Logan GD, Cowan WB. On the ability to inhibit thought and action: a theory of an act of control. Psychol Rev. 1984; 91: 295-327.

12. Ruchsow M, Groen G, Kiefer M, Buchheim A, Walter $H$, Martius $P$, Reiter $M$, Hermle L, Spitzer M, Ebert D, Falkenstein M. Response inhibition in borderline personality disorder: event-related potentials in a Go / Nogo task. J Neural Transm. 2008; 115(1): 127-133. 